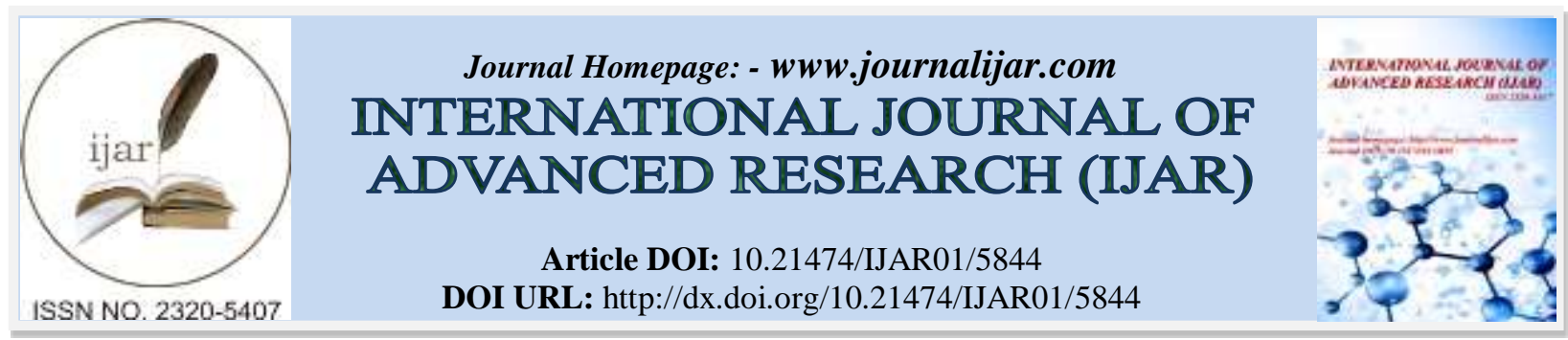

RESEARCH ARTICLE

\title{
SUSTAINING LITERACY IN THE PHILIPPINES: THE DUMAGAT EXPERIENCE.
}

\author{
"Valdez. Janet R. ${ }^{1}$, Galvez. Rosalyn ${ }^{2}$, Vistan. Alejandro Saratan ${ }^{3}$, Dr. Claudio Jr. Dayao ${ }^{4}$, Ryan. Vivar ${ }^{5}$ and \\ Elizabeth $^{6}$. \\ 1. La Consolacion University Philippines Graduate School. \\ 2. La Consolacion University Philippines Student Affairs and Services. \\ 3. La Consolacion University Philippines Quality Assurance Office. \\ 4. Manila City Hall. \\ 5. La Consolacion University Philippines Basic Education Department. \\ 6. La Consolacion University Philippines Night College.
}

\section{Manuscript Info}

(.........................

Manuscript History

Received: 12 September 2017

Final Accepted: 14 October 2017

Published: November 2017

\section{Abstract}

In 2008, the United Nations Educational, Scientific, and Cultural Organization (UNESCO) gave a more comprehensive and functional meaning of literacy by defining it as "a process of learning that enables individuals to achieve personal goals, to develop their knowledge and potential, and to participate fully in the community and wider society." This definition placed the Philippines $48^{\text {th }}$ in the world according to the World Data Atlas in 2015. The data configured a 96.6\% adult literacy rate in the Philippines which was an increase from its rate in 2013 at $96.4 \%$. The data included adults whose age ranged 15 years and above.It is in the interest of equality in sustaining literacy in the Philippines and developing a literate environment that these researchers shared interest in exploring the educational experience of the Dumagats in a remote area in Norzagaray, Bulacan.

This study aimed to sustain the literacy and quality of education of the indigenous people in Norzagaray, Bulacan called the Dumagats through a case study of the government's delivery of educational service to the community.

Copy Right, IJAR, 2017,. All rights reserved.

\section{Introduction:-}

The scope encompassed by the varying definitions of literacy necessitated the researchers to use the 2008 definition formulated by the United Nations Educational, Scientific, and Cultural Organization (UNESCO). The definition gave literacy a new meaning as "a process of learning that enables individuals to achieve personal goals, to develop their knowledge and potential, and to participate fully in the community and wider society." This definition shows a more comprehensive and functional context different from UNESCO's 1958 meaning of literacy which encompasses " the ability to read, write, comprehend, or embrace multiple skill domains to serve different purposes or to identify, interpret, create, communicate, and compute materials in different contexts."

With these definitions, the Philippines was ranked $48^{\text {th }}$ in the world according to the World Data Atlas in 2015. The data configured a $96.6 \%$ adult literacy rate in the Philippines which was an increase from its rate in 2013 at $96.4 \%$. The data included adults whose age ranged 15 years and above. The total percentage means that the population age 
15 and above possess the ability, with understanding, read and write a short, simple statement on their everyday life. Generally, 'literacy' also encompasses 'numeracy', the ability to make simple arithmetic calculations. This indicator is calculated by dividing the number of literates aged 15 years and over by the corresponding age group population and multiplying the result by 100 . The rate poses challenges and opportunities for sustaining literacy and developing a literate environment.

Globalization has opened civilization to new horizons and challenges towards literacy. In the Philippines, the first step towards the achievement and sustenance of literacy was the educational reform to a $\mathrm{K}$ to 12 Transition. The $\mathrm{K}$ to 12 Educational Reform poses threats on the successes of the traditional pedagogical ways and opportunities to build better academic communities with hopes on bringing a competitive population to a global labor market. The equal opportunities gained through literacy disregard societal categories and discriminatory demographic factors.

It is in the interest of equality in sustaining literacy in the Philippines that these researchers shared interest in exploring the educational experience of the Dumagats in a remote area in Norzagaray, Bulacan. With this in mind, the researchers proceeded to Norzagaray where an indigenous group of people called the Dumagats live. Norzagaray covers a portion of the Sierra Madre Mountain Range situated at the southeastern end of Bulacan bordering the Municipality of Montalban in Rizal Province, on the north by the Municipality of Doña Remedios Trinidad, on the west by the municipalities of Angat and Santa Maria, and on the southwest by the City of San Jose del Monte. More than one-third of the land area of Norzagaray falls within Angat Watershed that was delineated through Proclamation 71 dated March 10, 1927 covering a total area of some 62,310 hectares of the Sierra Madre in the Provinces of Bulacan and Nueva Ecija. The journey led the researchers to the 'Punduhan ng mga Dumagats' which is a ten-hectare property serving as a focal point for cultural and trading activities for the Agta-Bulos, Aeta or Dumagats tribes who had maintained their cultural traditions and customs by continuously living in the remotest place in the mountains. The Dumagats were named after naked people of the forest who had been referred to as the Aeta communities inhabiting the place. This geographical location of the Dumagats prevents the corruption of their indigenous customs, traditions, and livelihood which, on the other hand, prohibits literacy accessibility and growth.

Kral and Falk (2004) believe that the components of such a community form its capacity, and these components merge to achieve a state of well-being in the community. They include the intergenerational transmission of Indigenous knowledge, the skills and knowledge of alphabetic literacy practices and social capital.

\section{Statement of the Problem:-}

This study aimed to sustain the literacy and quality of education of the indigenous people in Norzagaray, Bulacan called the Dumagats through a case study of the government's delivery of educational service to the community. Specifically, the study found the answers to the following questions:

1. What is the literacy rate of the Dumagats in Norzagaray, Bulacan, particularly the nineteen (19) families living within the communal habitat in Punduhan?

2. What is the medium of instruction and communication among the Dumagats?

3. What materials do the Dumagats read in their everyday life and at school?

4. For what purposes and functions do people use reading and writing in everyday life in the community?

5. How do the Dumagats access free elementary education of the government?

6. What programs or projects can aid in sustaining the literacy of the Dumagats?

\section{Methodology:-}

The research is constructed as a case study of the literacy practices of the Dumagats of Norzagaray, Bulacan using the ethnographic techniques of observation, document collection, and recording of conversations and interviews. Quantitative data include the results of the interviews: unstructured and semi-structured covering content areas on literacy history and intergenerational practices, literacy acquisition and learning, literacy use in everyday life, adult education, employment needs, and literacy use in everyday life.

The procedures for data collection are as follows:

1. The researchers sought the help of the Municipality of Norzagaray who provided a guide to trudge the slopes of the Dumagats.

2. Data collection was done in a day where indigenous community members were sought for interviewing. The sampling was opportunistic, according to the availability of the interviewees. Key informants, including their volunteer trained teacher, were sought for interviewing. 
3. Observations were made of community members engaging in everyday education practices and events.

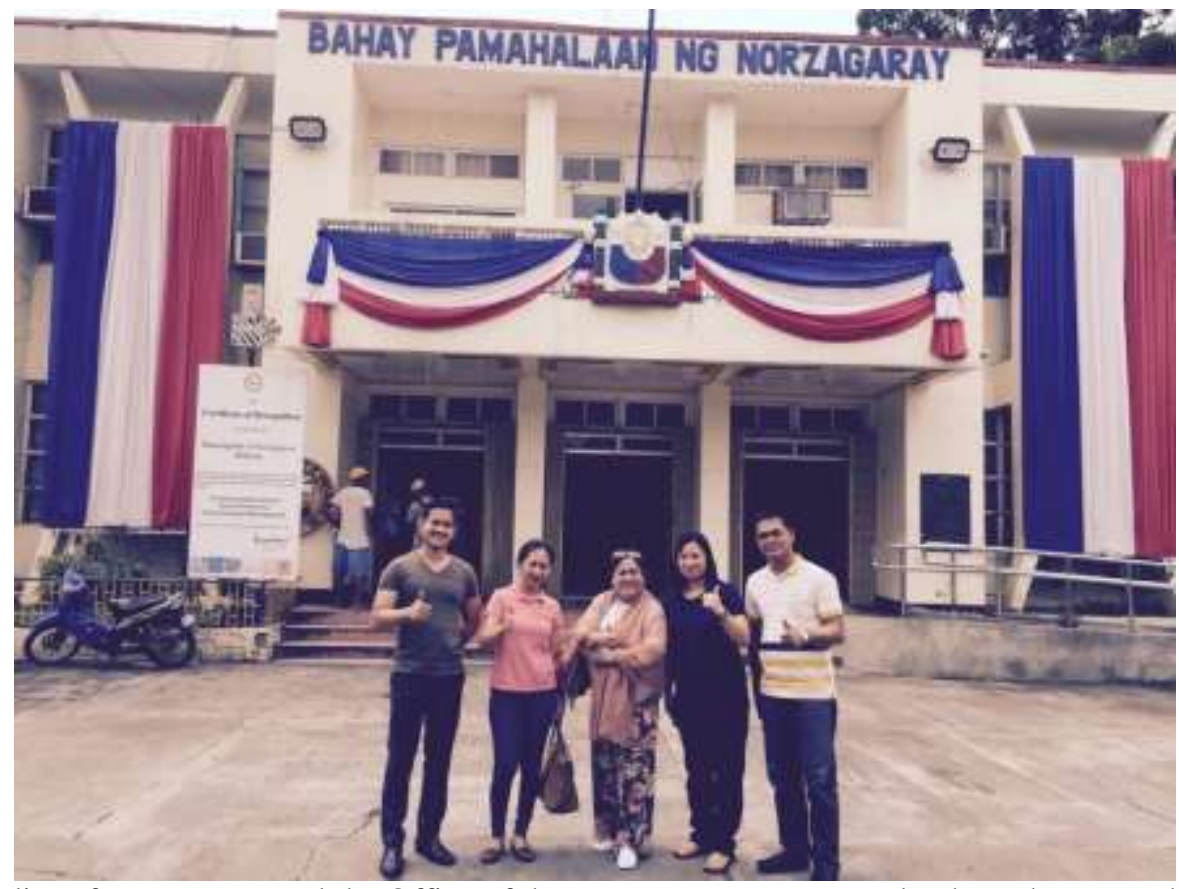

At the Municipality of Norzagaray and the Office of the Human Resources Head, where the researchers coordinated to seek permission to conduct the observation and interview and request a guide to bring them to the location of the Dumagats

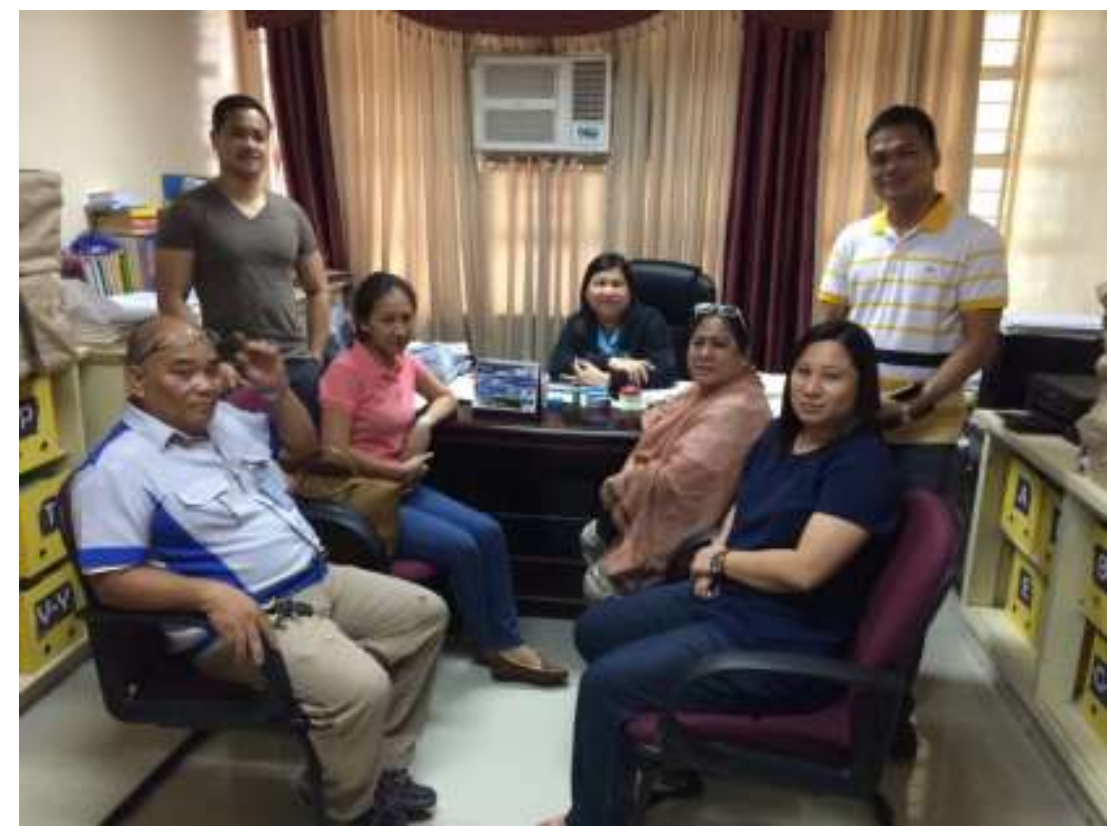



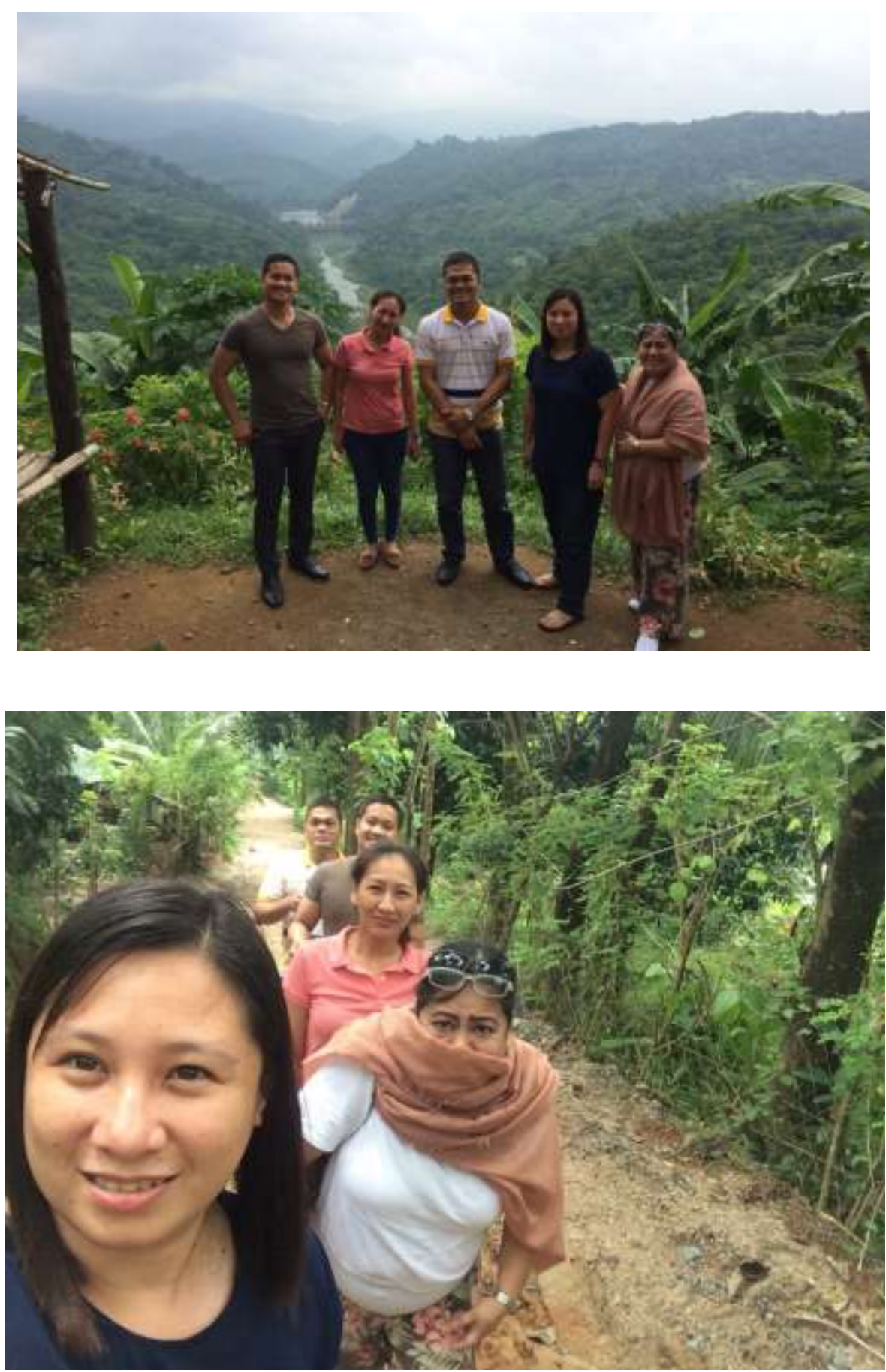

The researchers trudged through the terrains of the location of the Dumagats. 


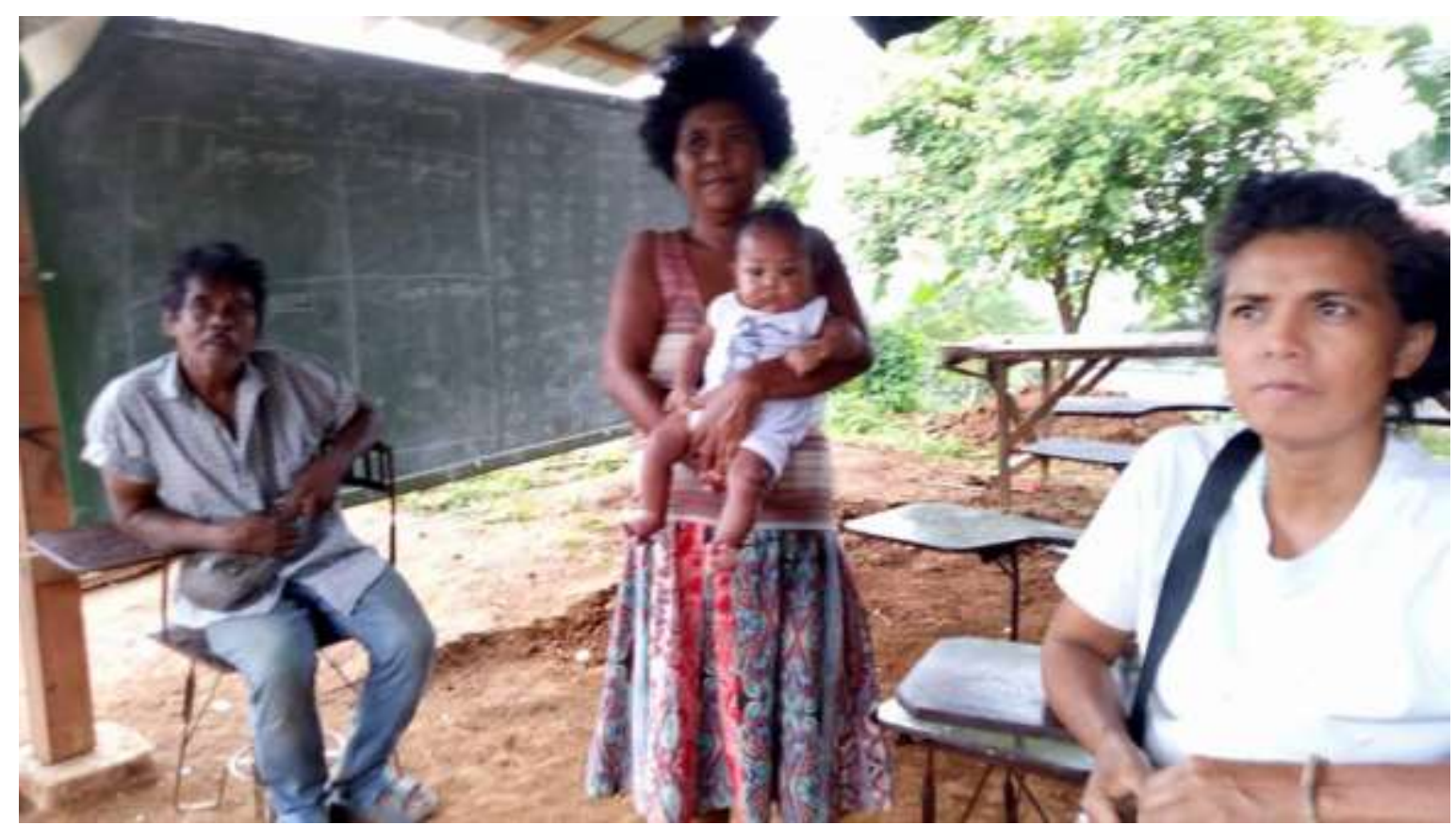

The volunteer trained teacher with other members of the Dumagat community.

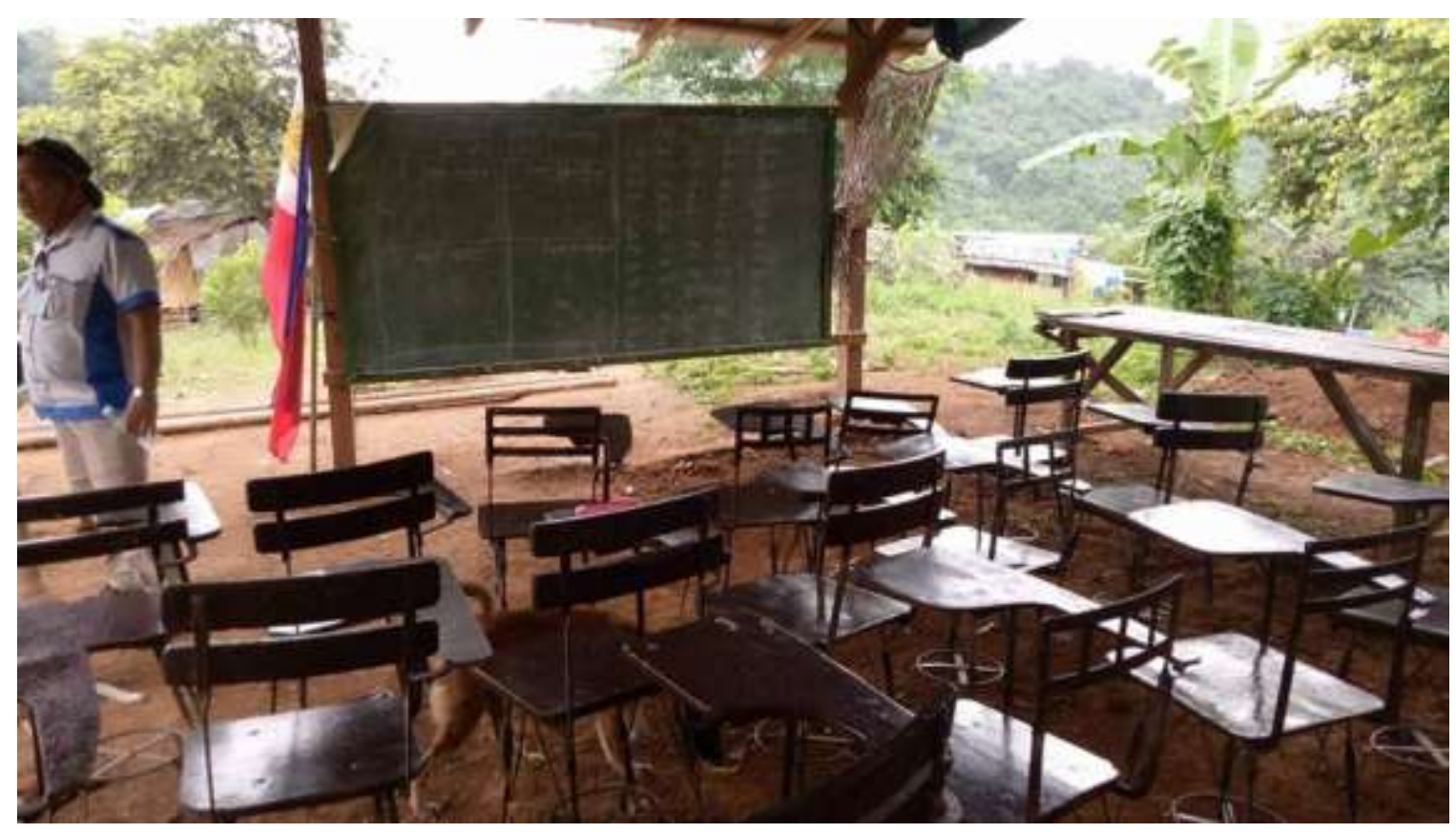




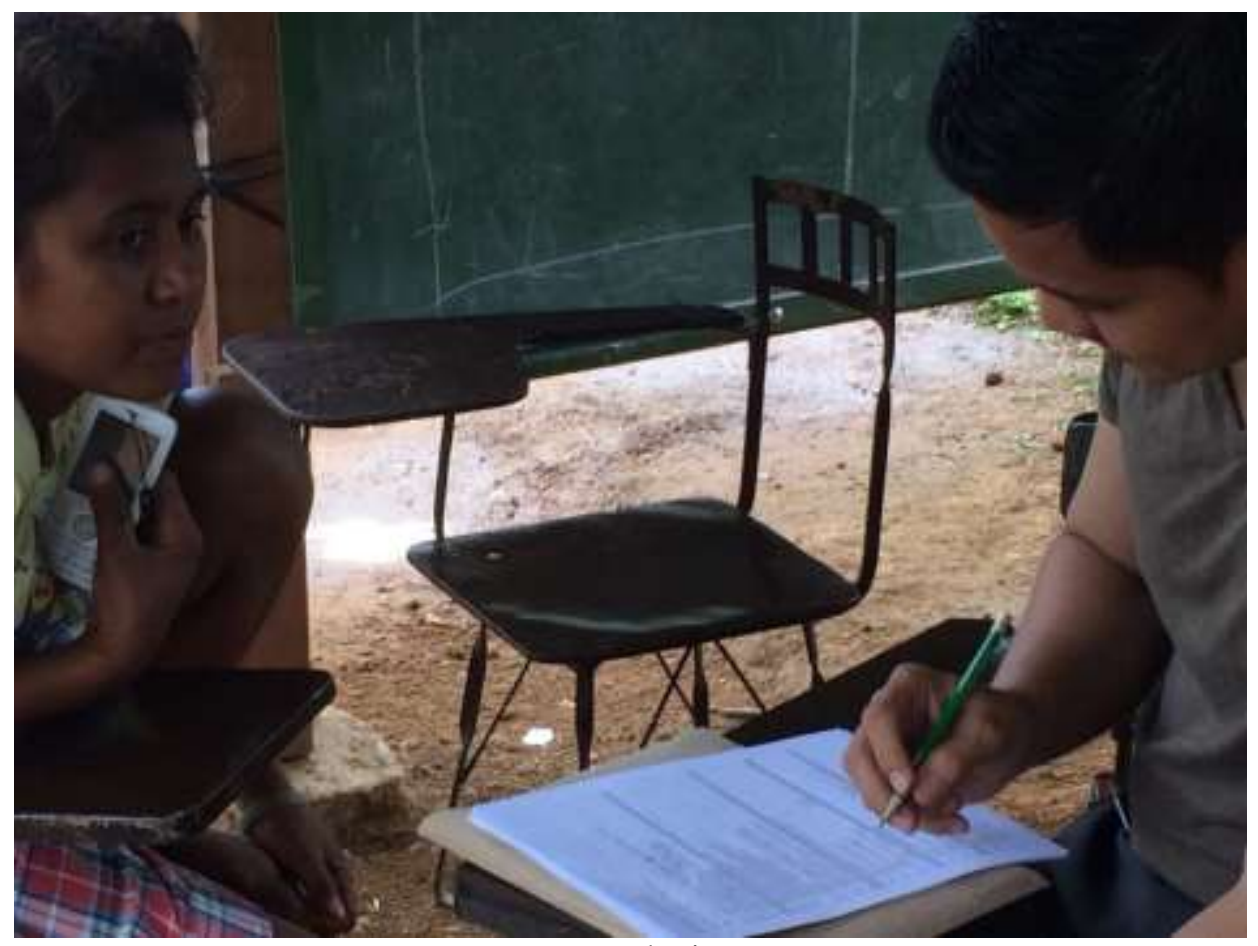

Data gathering

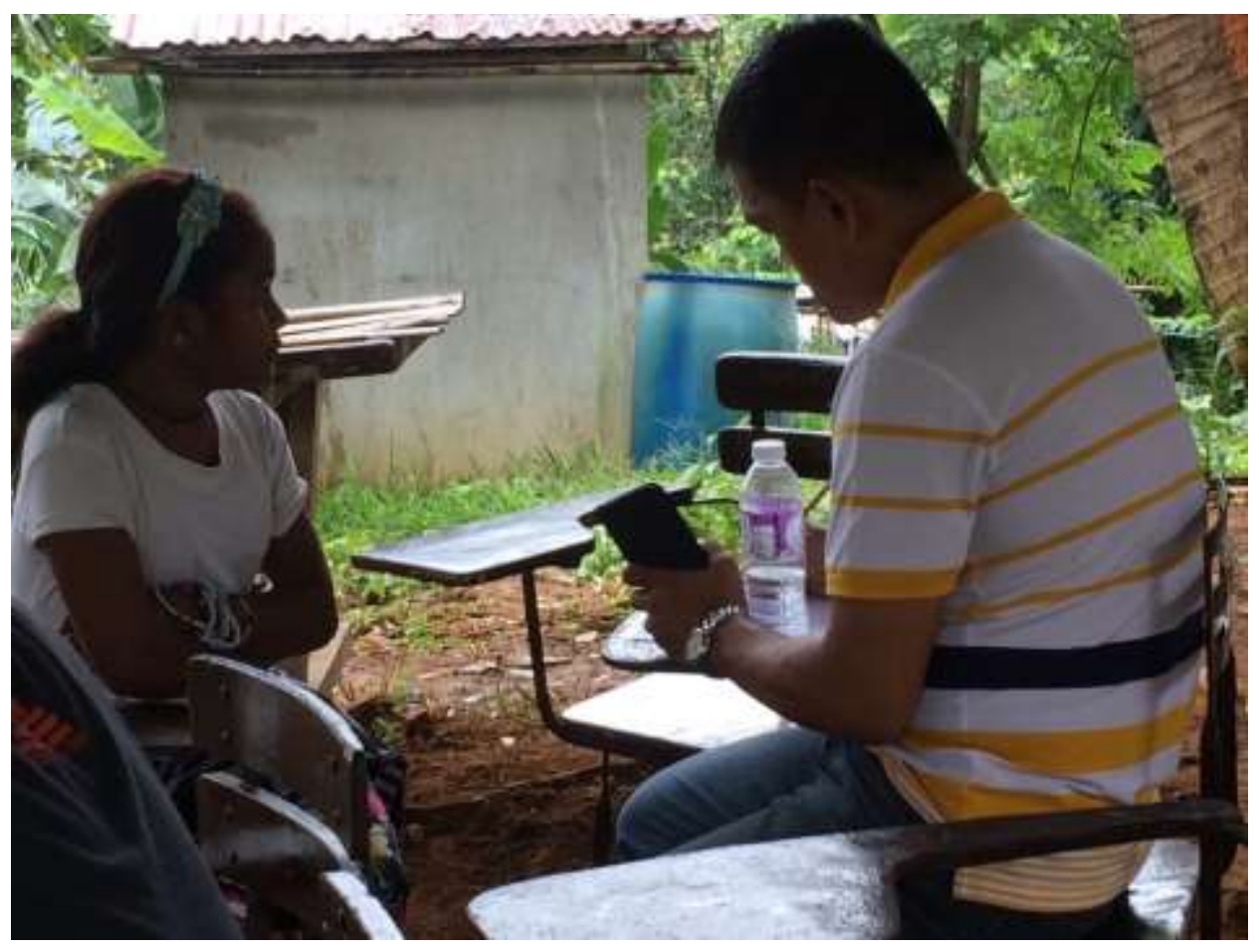




\section{Results and Discussions:-}

After the study, the researchers present the following findings:

Problem 1:-

The literacy rate of the Dumagats in Norzagaray, Bulacan, particularly the nineteen (19) families living within the communal habitat in Punduhan

The researchers found out that at the time of the observation, four (4) out of the fifty-six (56) or 7.14\% of the total respondents, ten years and above, can read and write. Reading literacy is described as being able to read in Filipino or Tagalog and in English. The four respondents who can read and write were tested in their ability to read, comprehend, and provide answer to the questions in the questionnaire. Their literacy was evident. On the other hand, the fifty-two Dumagats, aged ten years and above, are being taught to identify the English alphabet, read English syllables and three-letter words.

\section{Problem 2:-}

The medium of instruction and communication among the Dumagats

Fifty-six (56) or $100 \%$ of the respondents are trilinguals who can speak Tagalog or Filipino, bulos and kabuluan, which are the native dialects of the Dumagats in Norzagaray, Bulacan. Aside from these language and dialects, nine (9) respondents can speak palumagat which was a dialect learned from their parents.

The volunteer trained teacher who is one of them and considered the leader, as well as, the regular teacher who comes once a month, conduct their class in basic reading and writing in Tagalog which is the medium of instruction while their learners are taught the lesson to read and write in English.

\section{Problem 3:-}

Materials the Dumagats read in their everyday life and at school

The Dumagat learners were provided with pencils and paper for writing; however, books were nowhere in sight. The visible reading materials were the syllables and three-letter words in English written on the green board which serves as one wall of the class room. There is no access to any reading material which they desire to have.

\section{Problem 4:-}

Purposes and functions people use reading and writing in everyday life in the community

The Dumagats can survive the day without the necessity to read and write. The remoteness of the community shields them from reading materials that will allow them to practice reading. Their desire to read and write in Filipino and English sprung from the desire not to get lost when they are away from home.

\section{Problem 5:-}

The access of the Dumagats to free elementary education of the government

There is no school building in the vicinity of the Dumagats. They have a central location which functions as a classroom and place for their daily communal practices. They have dilapidated chairs with armrest, a green board which serves as a wall. There is no formal education provided to the Dumagats which is accessible to them. They have a non-salaried volunteer teacher who teaches the learners basic reading and writing. An Alternative Learning System (ALS) teacher who, also, teaches the Dumagats lessons in basic reading and writing in English, comes to them monthly.

\section{Problem 6:-}

\section{Programs and projects that could aid in sustaining literacy of the Dumagats}

The government provides the program of the Department of Education (DepEd) called Alternative Learning Ssystem (ALS) which allows an ALS teacher to come to the Punduhan ng mga Dumagats. This program brings the educational effort of the government to the remote areas with the aim of reducing, if not totally eradicating, illiteracy. Lessons on reading and writing are carried on daily by a volunteer-teacher from among them. She 
provides reinforcements and practices to the Dumagats who can not read and write even their names. Also, private individuals and groups reach out to the Dumagats to find and respond to their educational needs, such as the acquisition and sustenance of literacy.

\section{Conclusion and Recommendations:-}

In the light of the following findings, the following observations and recommendations are drawn:

1. The small portion (3.4\%) of the Philippine population who does not possess the ability to read and write include the Dumagats found in Norzagaray, Bulacan.

2. The Philippines maintains a high literacy rate; however, the programs and projects of the government in the sustenance and improvement of literacy do not suffice the needs of the Dumagats to enable them to gain literacy or the ability to read and write.

3. The Dumagats prioritize daily communal subsistence than the acquisition of the ability to read and write.

4. The government needs to find the cultural minorities who live in the remotest part of the provinces and provide them functional literacy that would include better means of livelihood.

5. The government should look into a specialized curriculum that will use alternative educational modalities in pursuit of sustaining literacy in the Philippines.

\section{References:-}

1. Huang, S., \& Liu, S. (2016). Discrimination and incorporation of Taiwanese indigenous Austronesian peoples. Asian Ethnicity, 17(2), 294-312. doi:10.1080/14631369.2015.1112726

2. Kral and Falk (2004). What is all that learning for? Indigenous adult English literacy practices, training, community capacity and health. Commonwealth of Australia.

3. McKAY, T. (2017). BUILDING A COMMUNITY OF LIFELONG LEARNING. Phi Kappa Phi Forum, 97(2), $10-13$.

4. Mei Kuin, L., McNaughton, S., Amituanai-Toloa, M., Turner, R., \& Hsiao, S. (2009). Sustained Acceleration of Achievement in Reading Comprehension: The New Zealand Experience. Reading Research Quarterly, 44(1), 30-56.

5. Retrieved from Knoema World Data Atlas https://knoema.com/atlas/Philippines/topics/ Education/Literacy/Adult-literacy-rate on August 27, 2017. 